\title{
Cambios reológicos del queso Colonia durante el proceso de maduración
}

\author{
Crosa, M. J. (1), Harispe, R. (2), Márquez, R. ${ }^{(1)}$, Pelaggio, R. ${ }^{(1)}$, Repiso, L. ${ }^{(1)}$, Silvera, C. ${ }^{(3)}$ \\ Contacto: mcrosa@latu.org.uy \\ (1) Gerencia de Proyectos Alimentarios. Investigación, Desarrollo e Innovación, Laboratorio Tecnológico del Uruguay \\ (LATU) - (2) Naturalia S.R.L. - ${ }^{(3)}$ Universidad Católica del Uruguay Dámaso Antonio Larrañaga (UCU)
}

Recibido: 26/2/2008 - Aprobado: 15/12/2008

\begin{abstract}
Resumen
El queso Colonia es un queso típico uruguayo, elaborado según los criterios de calidad y tradición quesera de los inmigrantes suizos radicados en la cuenca lechera del departamento de Colonia. En la actualidad no se reporta información publicada acerca de los cambios reológicos que ocurren en el queso durante su maduración. Su investigación y publicación aportan conocimiento para la difusión de un proceso que aún no presenta denominación de origen protegida.

En el presente trabajo se midieron los cambios reológicos mediante el ensayo de relajación-compresión, durante el proceso de maduración realizado a $8^{\circ} \mathrm{C}$ y $85 \%$ de humedad relativa hasta el día 13. Los resultados obtenidos manifiestan la existencia de un cambio importante del comportamiento a partir del día 11 de maduración, momento en que ocurre un notorio ablandamiento del queso. Esto concuerda con la práctica industrial que tradicionalmente realiza el cambio de los quesos para continuar su maduración en cámara caliente a partir del onceavo día.

Este estudio demuestra la importancia de esperar hasta el onceavo día para asegurar la elasticidad necesaria en el queso para una adecuada formación de ojos en la cámara caliente.

Palabras clave: queso Colonia, maduración, reología de quesos, compresión, relajación.

$\underline{\text { Abstract }}$

"Colonia" cheese is a typical Uruguayan cheese, elaborated following the quality standards and cheese making tradition of the swiss inmigrants established at the uruguayan department of Colonia and sourrondings. Actually there is no available information about the reological changes that happen in this kind of cheese during its ripeness. The study and publication of this process (which does not present a protected designation of origin (DOP) yet) gives knowledge for its spread.

Rheological changes were analyzed with the stress relaxation test along the ripeness process made at $8{ }^{\circ} \mathrm{C}$ and a humidity of $85 \%$ until the 13th day. The results indicate that an important performance change exists after the 11th ripeness day, where a remarkable tenderness change takes place. This result allows to confirm the importance of letting the ripeness run at low temperatures for at least 11 days ensuring the necessary elasticity for eye formation, consistent with the industrial practice that changes environmental conditions of ripeness (temperature and relative humidity) at the eleventh day of the production.

Keys words: cheese ripeness, rheology, stress-relaxation test
\end{abstract}

\section{Introducción}

El queso Colonia es un queso típico uruguayo, elaborado según los criterios de calidad y tradición quesera de los inmigrantes suizos radicados en la cuenca lechera del departamento de Colonia. En la actualidad no se reporta información publicada acerca de los cambios reológicos que ocurren en el queso durante su maduración. Su investigación y publicación aportan conocimiento para la difusión de un proceso que aún no presenta denominación de origen protegida.

La textura del queso es un parámetro importante para su clasificación y apreciación de su calidad. La textura depende del proceso de elaboración desde sus primeras etapas. Si se divide finamente la cuajada, se promueve el desuerado que va influir en la textura final. Similar efecto se observa si se prolonga la agitación de la cuajada en el suero o aumentando la temperatura de cocción. Una vez que la estructura básica se ha formado, el proceso de maduración genera la textura final del queso. Este proceso está influenciado por su tamaño, forma y condiciones de maduración, principalmente por el tiempo, temperatura, humedad, bacterias y enzimas presentes. La humedad, el contenido graso, el grado hidrólisis de la lactosa, grasa y proteínas definen el comportamiento reológico del queso. Cada tipo de queso presenta un atributo en textura característico, son posibles atributos los opuestos de "elástico" para el queso Muzzarella, y por "desgranarse" cuando se somete a presión para el queso Parmesano.

Estudios previos (AATA, 1999) aplican diferentes métodos para medir las propiedades reológicas según el tipo de queso. Por ejemplo, para quesos de pasta dura y semidura se recomienda la compresión uniaxial hasta el punto de fractura. La técnica de compresión-relajación es recomendada para el estudio de las propiedades viscoelásticas, usado ampliamente para quesos italianos.

El queso Colonia se caracteriza por la presencia de ojos en su interior, pasta consistente, algo elástica y de sabor suave. Según la tradición quesera, el proceso de maduración ocurre en cuatro etapas, las primeras 12 - 48 horas son para el oreo de entre $4-6^{\circ} \mathrm{C}$, luego 10 - 12 días tienen una estadía en cámaras entre 8 y $11{ }^{\circ} \mathrm{C}$ de temperatura. En la tercera etapa, los quesos se someten a temperaturas entre 20 y $24^{\circ} \mathrm{C}$, donde ocurre la formación de los ojos característicos del queso, y por último se vuelven a cámara templada - fría $<10^{\circ} \mathrm{C}$.

Es conocida la necesidad de la industria por acelerar los procesos y disminuir los tiempos de maduración, con el objetivo de disminuir costos. Hasta el momento no existen estudios que justifiquen el periodo de permanencia de los quesos en las cámaras, ni medida de los cambios que ocurren durante este período.

El objetivo de este estudio es conocer el cambio de las propiedades reológicas del queso Colonia durante el proceso de maduración en cámara fría. En esta primera etapa del proceso, es importante obtener una masa suficientemente suave y elástica para la futura formación de los ojos. El conocimiento de los cambios en las propiedades reológicas de esta etapa aportará datos relevantes para la definición de las condiciones de maduración del queso Colonia. 


\section{Metodología}

Se elaboró queso en tina de 1.100 litros de leche pasteurizada, usando como fermentos bacterias Lácticas y Priopiónicas. El cuajo se cortó en granos medios de 6 a $7 \mathrm{~mm}$ de diámetro, se agitó durante 15 minutos a $32{ }^{\circ} \mathrm{C}$ y se coció a $48{ }^{\circ} \mathrm{C}$ durante 30 a 40 minutos. La cuajada se pescó, pre-prensó y se llevó a moldes para quesos de $7 \mathrm{~kg}$ peso final. Se prensó durante cuatro horas, rotando el queso cuatro veces. Se saló en tina de salmuera durante 48 horas, se mantuvo en cámara de oreo de $7{ }^{\circ} \mathrm{C}$ durante 12 horas y finalmente se pasó el queso a la cámara de maduración.

Se estudió el cambio reológico del queso durante la primera etapa del proceso de maduración, en cámara fría de 8 a $12{ }^{\circ} \mathrm{C}$ y $85 \%$ de humedad.

Se realizaron dos experiencias distanciadas en el tiempo para asegurar la independencia de los datos obtenidos. En la primera fase del estudio, desarrollada en 2004, se efectuaron medidas de textura en la zona media del queso en los días 4, 5, 10, 11, 12 y 13 de maduración, mientras que en los estudios confirmatorios de 2007 las muestras fueron tomadas en los días de maduración 1, 6 y 13. Las condiciones de maduración de los quesos fueron $8{ }^{\circ} \mathrm{C}$ de temperatura y $85 \%$ de humedad.

Para cada condición se cortaron en la zona media de un queso ocho muestras cilíndricas por queso, de $3.50 \pm 0.05 \mathrm{~cm}$ de diámetro y $4.00 \pm 0.05$ $\mathrm{cm}$ de altura, se termostatizaron a una temperatura definida y se aplicó el ensayo de compresión - relajación. La compresión uniaxial fue hasta un $20 \%$ de la altura original de la pieza, con una velocidad de deformación de $50 \mathrm{~mm} / \mathrm{mín}$ con el equipo INSTRON MODELO 1000 y el sistema de adquisición de datos INI-DAQ MX NATIONAL INSTRUMENTS. Se usó el accesorio de compresión de $2.5 \mathrm{~cm}$ de diámetro, modelo T372-63. Se midió la variación de fuerza al tiempo " $\mathrm{t}$ " $(\mathrm{Ft})$ y la fuerza al inicio de la relajación (Fmax) (AATA, 1999; Sundaram Gunasekaram, 2003).

La metodología seguida fue la misma en ambos ensayos, a excepción de la temperatura de termostatización de la muestra para la medida de textura. En el primer ensayo la temperatura de termostatizacion de la muestra fue a $12{ }^{\circ} \mathrm{C}$ en todos los días de maduración estudiados. En experiencias posteriores se comprobó una disminución de la dispersión del ensayo cuando la temperatura de la pieza se acerca a la temperatura ambiente. Por lo tanto, en el segundo ensayo se aumentó la temperatura de termostatización de la muestra a $18{ }^{\circ} \mathrm{C}$. La diferencia de temperatura de las piezas durante el ensayo no permite un análisis conjunto de los resultados, debido a la gran dependencia de la medida con la temperatura. Sin embargo, es posible comparar entre sí la similitud de las tendencias.

\section{Resultados y Discusión}

En los Gráficos 1 y 2 se presentan las curvas de relajación, expresadas como la relación de la fuerza al tiempo " $\mathrm{t}$ " $(\mathrm{Ft})$ y la fuerza al inicio de la relajación (Fmax). En estos gráficos se observa un comportamiento similar en los días de maduración 1 al 10, pero a partir del décimo día de maduración ocurre un cambio en las curvas de relajación de los quesos.

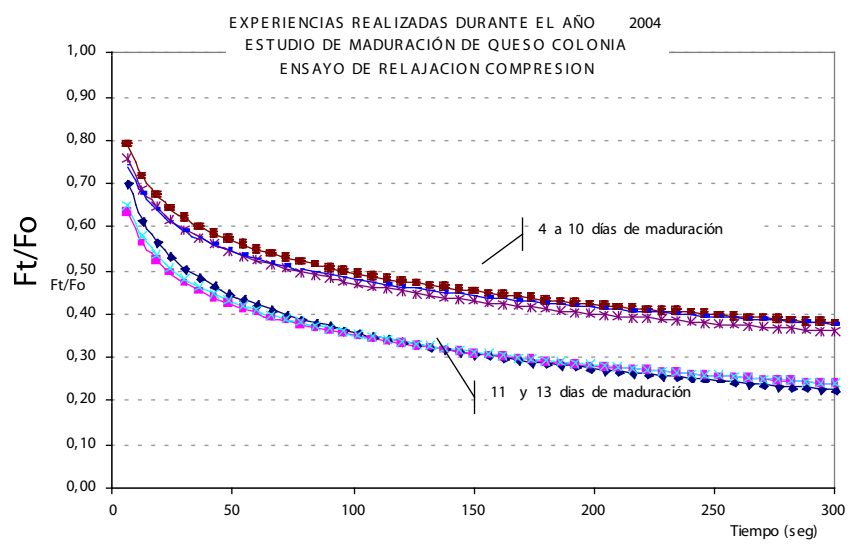

Gráfico 1. Curva de relajación-compresión en diferentes días de maduración durante el primer ensayo.
ESTUDIO DE MADURACION DE QUESOS COLONIA ENSAYO DE RELAJACION - COMPRESION EXPERIENCIAS 2007

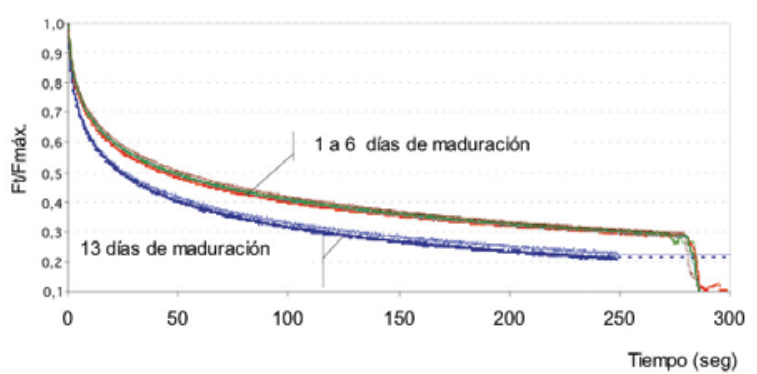

Gráfico 2. Curva de relajación-compresión en diferentes días de maduración durante el segundo ensayo.

Con el objetivo de cuantificar los cambios visualizados, se normalizan las curvas obtenidas en la ecuación: (Fmax * t)/(Fmax $-\mathrm{Ft})=\mathrm{K} 1+\mathrm{K} 2 * \mathrm{t}$ (Peleg and Normand, 1983). En el Gráfico 3 se presentan las curvas obtenidas. El valor de K1 representa la velocidad del decaimiento inicial de la fuerza, y el valor de K2 corresponde con el valor asintótico de la fuerza normalizada. En la Tabla 1 se informan los valores obtenidos de ambas experiencias.

NORMALIZACION DE LA FUERZA ENSAYO COMPRESIÓN - RELAJACIÓN

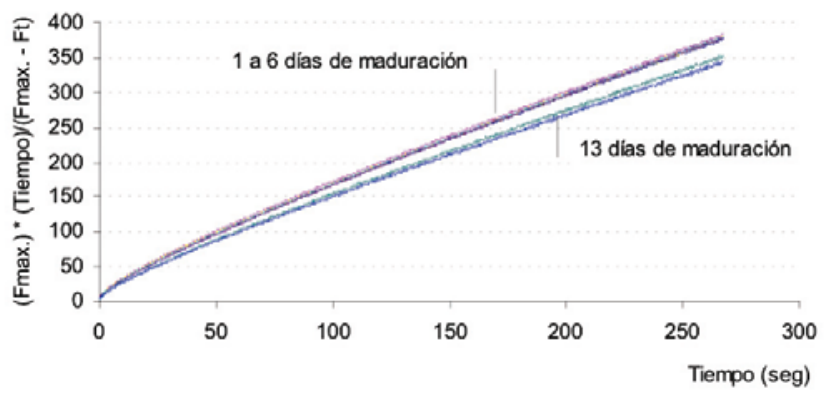

Gráfico 3. Normalización de las curvas obtenidas según ecuación Peleg and Normand, 1983.

\begin{tabular}{|c|c|c|c|}
\hline \multicolumn{4}{|c|}{$\begin{array}{l}\text { NORMALIZACIÓN DE LA FUERZA según Peleg and } \\
\text { Normand, } 1983\end{array}$} \\
\hline & & $\begin{array}{c}\text { K1 } \\
\text { (seg) }\end{array}$ & $\mathrm{K} 2$ \\
\hline \multirow{2}{*}{$\begin{array}{c}\text { Temperatura }= \\
12{ }^{\circ} \mathrm{C} \\
\text { Ensayo } \\
\text { relajación } \\
\text { compresión }\end{array}$} & $\begin{array}{l}\text { Días de maduración } 4,5 \\
\text { y } 10 \\
\end{array}$ & $29 \pm 4$ & $\begin{array}{r}1.59 \\
\pm 0.04 \\
\end{array}$ \\
\hline & $\begin{array}{l}\text { Días de maduración } \\
11,12 \text { y } 13\end{array}$ & $20 \pm 4$ & $\begin{array}{l}1.31 \\
\pm 0.04\end{array}$ \\
\hline \multirow{2}{*}{$\begin{array}{c}\text { Temperatura }= \\
18^{\circ} \mathrm{C} \\
\text { Ensayo } \\
\text { relajación } \\
\text { compresión }\end{array}$} & $\begin{array}{l}\text { Días de maduración } \\
\qquad 1 \text { y } 6 \\
\end{array}$ & $30 \pm 2$ & $\begin{array}{r}1.33 \\
\pm 0.01 \\
\end{array}$ \\
\hline & $\begin{array}{l}\text { Día de maduración } \\
13\end{array}$ & $25 \pm 2$ & $\begin{array}{l}1.22 \\
\pm 0.01\end{array}$ \\
\hline & de confianza al $95 \%$ & media & \\
\hline
\end{tabular}

Tabla 1. Resultados obtenidos por normalización fuerza ecuación Peleg and Normand, 1983. 
Los valores de $\mathrm{K} 1$ y de $\mathrm{K} 2$ entre los días 1 a 10 de maduración no presentaron diferencias significativas con un intervalo de confianza al $95 \%$ de la media. Tampoco se detectaron diferencias significativas de las constantes entre los días 11 al 13. Sin embargo, se detecta diferencia significativa al $95 \%$, entre los valores del día 10 y 11 , en la experiencia realizada durante 2004, tendencia confirmada en 2007.

En el Gráfico 4 se presentan los valores de fuerza máxima obtenidos durante las experiencias de 2007, observándose también una disminución significativa de la fuerza en el día 13, que se relaciona con la disminución de dureza del queso.

\section{SEGUIMIENTO DUREZA QUESO COLONIA} EXPERIENCIAS 2007

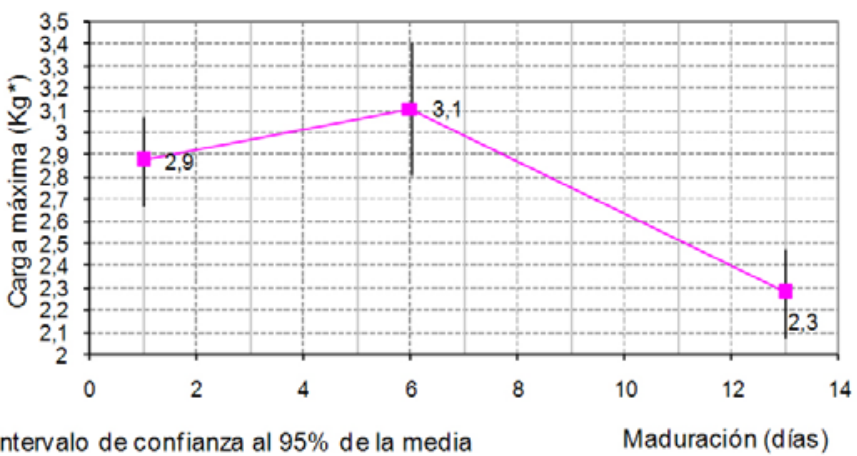

Gráfico 4. Seguimiento de la dureza del queso Colonia durante su maduración.

\section{Conclusiones}

Las propiedades reológicas del queso Colonia durante la maduración no presentan cambios significativos en los primeros 10 días de estadía en la cámara fría a $8{ }^{\circ} \mathrm{C}$ y $85 \%$ humedad relativa. Sin embargo, a partir del día 11 de estadía ocurre una significativa disminución de la dureza y elasticidad. Este es un cambio muy positivo y necesario para la futura formación de ojos en el queso en la cámara caliente.

Los resultados de este estudio informan la importancia de esperar hasta el onceavo día para cambiar los quesos a la cámara caliente.

\section{Reconocimientos}

- Programa de Desarrollo Tecnológico. Ministerio de Educación y Cultura, Uruguay.

- Téc. Lech. Pablo Wurth, Jefe de Planta de Elaboración, Naturalia S.R.L.

- Bach. Quím. M. Inés Dios, analista de laboratorio.

- LATU: Centro de Información Técnica.

- LATU: Departamento de Productos Lácteos, Cárnicos, Hortifrutícolas y de la Colmena.

\section{Referencias}

\section{- ASOCIACIÓN ARGENTINA DE TECNÓLOGOS}

ALIMENTARIOS. 1er. Seminario Internacional y Workshop. Análisis Sensoriales de los Alimentos: octubre 13-15 de 1999. Buenos Aires: AATA, 1999.

- GONZÁLEZ VIÑAS, Miguel Ángel, et al. Relationship between sensory and instrumental measurements of texture for artisanal and industrial manchego cheese. En: Journal of Sensory Studies. 2007, 22(4):462-476.

- GUNASEKARAN, Sundaram, AK, M. Mehmet. Cheese Rheology and Texture. Boca Raton: CRC Press, 2003.

- PELEG, M.; NORMAND, M.D. Comparison of two methods for stress relaxation data representation of solid foods. En: Rheolica Acta. 1983, (22):108-113.

- STEFFE, James F. Rheological methods in food process engineering. 2a ed. Michigan: Freeman, 1996. 